\title{
CORTES DE DROGAS NO BRASIL: A HERANÇA DO PROJETO DE FREDERICO WESTPHALEN/RS
}

\section{DRUG COURTS IN BRAZIL: THE HERITAGE FROM FREDERICO WESTPHALEN'S PROJECT}

\author{
Daniel Pulcherio Fensterseifer* \\ Lisiane dos Santos Welter**
}

\begin{abstract}
Resumo: O presente trabalho discute aspectos históricos e conceituais, bem como apresenta os resultados da experiência do Programa de Justiça Terapêutica com adolescentes da comarca de Frederico Westphalen/RS. O referido projeto, que contou com o trabalho dos cursos de Direito, Enfermagem, Psicologia e Serviço Social da Universidade Regional Integrada do Alto Uruguai e das Missões - URI/FW e com a colaboração do Poder Judiciário, Ministério Público e Prefeitura Municipal de Frederico Westphalen/RS teve duração de 06 (seis) meses. Apesar de o projeto não ter sido renovado em razão da baixa demanda encaminhada ao programa, importantes conclusões puderam ser extraídas dessa breve experiência, especialmente no que tange a sua estrutura organizacional e metodológica. Evidenciou-se ser possível desenvolver o programa de acordo com os componentes-chave propostos pela comunidade profissional e acadêmica internacional, sem que isso ferisse qualquer pressuposto constitucional ou legal do nosso ordenamento jurídico.
\end{abstract}

Palavras-chave: Justiça Terapêutica; Drogas; Tratamento; Adolescentes; Crime

\begin{abstract}
This work discusses historic and conceptual aspects, as well as presents results taken from the experience of Drug Courts Program with adolescents from Frederico Westphalen's court. The project last for six months. It had the help of Law, Nursing, Psychology and Social Work undergraduate courses from Universidade Regional Integrada do Alto Uruguai e das Missões - URI/FW, and it had the collaboration of the Judicial Court, the Public Prosecution and the Municipal Government of Frederico Westphalen. Despite the project has not been renewed due to low demand to the program, a few important conclusions could be taken from this short experience, conclusions which are mainly related to the organizational and methodological structures. We highlight it was possible to develop the program according to its key-components proposed by the international academic and professional community, and it did not damage any constitutional or legal assumption of our legal order.
\end{abstract}

Key-words: Drug Courts; Drugs; Treatment; Juveniles; Crime

\footnotetext{
* Doutorando (bolsista CAPES) e Mestre em Ciências Criminais pela PUCRS. Professor de Direito da Universidade Regional Integrada do Alto Uruguai e das Missões - URI/FW. Rio Grande do Sul. Líder do Grupo de Pesquisa em TherapeuticJurisprudence. Membro da diretoria da AsociaciónIberoamericana de JusticiaTerapéutica. Diretor Financeiro da Associação Brasileira de Justiça Terapêutica.http://lattes.cnpq.br/5083972295848538. E-mail: danielpulcherio@uri.edu.br

** Psicóloga, graduada pela Universidade Regional do Alto Uruguai e das Missões. Rio Grande do Sul. Residente em Saúde Mental na Universidade Federal de Santa Maria/RS.http://lattes.cnpq.br/9752114551031129. E-mail: lisi_welter@hotmail.com
} 


\section{INTRODUÇÃO}

A proposta de realização do presente estudo se dá a partir de três pontos chave: primeiramente, sabe-se que o índice de consumo de drogas lícitas e ilícitas entre os brasileiros é muito alto; em segundo lugar, não podemos fugir da constatação de que grande parte das manifestações violentas - e destaca-se o cometimento de crimes - possui o uso de substâncias entorpecentes como fator de grande importância; por fim, acredita-se que a implantação do programa de Justiça Terapêutica no Brasil possa ser uma alternativa interessante de abordagem da criminalidade associada ao abuso de drogas, tendo como base experiências internacionais emDrugTreatmentCourts as quais vem apresentando resultados satisfatórios nos países em que já foram implantados esse tipo de tribunal.

De acordo com pesquisas publicadas nos anos de 2001 (CARLINI et. al. 2002) e 2005 (CARLINI, et. al. 2006) pelo Centro Brasileiro de Informações sobre Drogas Psicotrópicas - CEBRID -, constata-se que houve um aumento no consumo de entorpecentes pela população brasileira, tanto em relação às drogas ilícitas como às lícitas.

Em relação à dependência química, a mesma pesquisa também trouxe resultados importantes dentro do contexto da presente pesquisa. De acordo com o CEBRID, a adição às drogas elevou-se nas faixas etárias de 12 a 17 anos de idade, assim como entre os jovens de 18 a 24 anos. Dessa constatação podemos sugerir que o consumo de drogas vem sendo manejado de forma mais nociva dentre os jovens.

Mais recentemente, no ano de 2010 (CARLINI et. al. 2010), foi publicado novo levantamento realizado pelo CEBRID, tendo como amostra estudantes das redes pública e particular de ensino, na qual se verificou uma diminuição no consumo de drogas ilícitas em comparação com o levantamento publicado no ano de 2004 (GALDUROZ, et. al. 2004). Contudo, de acordo com os levantamentos, percebeu-se que o uso de cocaína voltou a crescer e de modo estatisticamente significante.

Como se pode perceber, o consumo de drogas é uma questão preocupante do ponto de vista da saúde pública, e que deve também ser entendido como matéria de interesse da justiça quando esse consumo configura-se como combustível para a prática de crimes.O abuso de substâncias psicotrópicas é considerado um fator de risco para o comportamento delinquente, justamente por ser um "importante desencadeador de mudanças no comportamento e na personalidade, geralmente, sendo prejudicial às interações sociais e 
pessoais" (TAVARES, SHEFFER, ALMEIDA, 2012, p. 90) e aumentando as chances de ocorrência de crimes como o homicídio, violência doméstica e delitos de trânsito. Nesse sentido, cumpre destacar que, no mesmo estudo foi encontrado que $60 \%$ da amostra de apenados abusavam de algum tipo de droga, sendo "verificada a associação estatisticamente significativa positiva com a reincidência criminal; com crime de roubo; com o traço de raiva; com o temperamento agressivo" (TAVARES, SHEFFER, ALMEIDA, 2012, p. 91).

No âmbito familiar a situação não é diferente. O consumo de drogas é um facilitador da violência, sendo capaz de aumentar em $59 \%$ as chances de agressão por parte de parceiros que usam o álcool frequentemente e em quase seis vezes em relação ao uso de outras drogas (VIEIRA, PERDONA, SANTOS, 2011). Nesse mesmo sentido, encontrou-se que em $92 \%$ dos casos de violência doméstica o uso de drogas está presente (ZILBERMAN, BLUME, 2005).

Como se percebe, são inúmeros os delitos em que o consumo de drogas se apresenta como um elemento facilitador, fazendo com que esse abuso deixe de ser um problema apenas de saúde pública e passe a configurar, também, uma preocupação de matéria judicial. Diante disso, o Direito tem a obrigação ética de reconhecer essa circunstância e buscar meios de abordagem mais adequados a esse tipo de criminalidade.

Pensando-se exatamente dessa maneira, no ano de 1989, na cidade de Miami, Estados Unidos, surgiu a primeira DrugTreatmentCourt que, ensejaram o desenvolvimento do que foi denominado de programa de Justiça Terapêutica (FENSTERSEIFER, 2012).Em diversos países, como nos Estados Unidos, Canadá, Austrália, Porto Rico, Chile, dentre outros, foi observado que a partir do engajamento dos acusados em um tratamento à dependência química substitutivo ao processo penal tradicional, houve significativa redução da taxa de reincidência e diminuição dos gastos do Estado, bem como, a implementação de inúmeros benefícios na vida do participante, tanto em relação à sua situação perante a justiça, como no que diz respeito à sua saúde e vínculos pessoais, benefícios esses que não podem ser ignorados (FENSTERSEIFER, 2012).

Dessa forma, vislumbra-se a substancial importância da presente pesquisa no cenário acadêmico e prático-forense, na medida em que a partir da implantação de um modelo de Justiça Terapêutica no Brasil, pode ser possível oferecer uma alternativa mais adequada e eficiente ao usuário de drogas que, em razão da sua condição de abusador, envolveu-se com a justiça criminal. 


\section{O SURGIMENTO DAS CORTES DE DROGAS AMERICANAS}

Na década de 60, os Estados Unidos passavam por grandes movimentações culturais, período este que marcado pela psicodelia e pela cultuação da droga como fonte de inspiração artística. Nessa mesma década, os americanos ainda passavam pela guerra do Vietnã, que terminou com a derrota dos Estados Unidos depois de um longo período de sofrimento que contabilizou milhares de mortes. Tratou-se de uma época de posições antagônicas, tendo-se de um lado movimentos sociais combativos, tais como os movimentos juvenil, feminista e dos negros, muitos deles contra a guerra e que podiam ser caracterizados por uma força não apenas discursiva, e de outro lado o movimento hippie, igualmente contrário à guerra, mas pregando unicamente a paz e o amor.

A popularização do uso de drogas tornou-se evidente em todo o país e o governo americano buscou meios de inibir a disseminação do uso e das suas consequências. No ano de 1966 foi aprovada a NarcoticAddictandRehabilitationAct, a qual concedia competência aos Estados americanos para encaminhar os acusados de cometer crimes relacionados ao uso de drogas para tratamento por tempo indeterminado como alternativa à prisão (LIMA, 2011).

Por outro lado, o que era verificado é que a criminalidade associada a droga estava em crescimento e a população carcerária estava se tornando cada vez mais caracterizada por essa circunstância. Em razão disso, nos anos 70 o governo americano criou cortes especializadas para atenderem a demanda proveniente dos delitos menos graves relacionados aos entorpecentes, denominadas de Fast-TrackCourts ou ExpedictedDrug Case ManegementCourts. Essas cortes, em que pese a distinção conceitual e o fato de que ofereciam procedimentos diferenciados, ainda eram muito mais focadas em um caráter de seleridade da aplicação da resposta estatal do que no tratamento propriamente dito, possuindo a finalidade de dar fôlego ao já abarrotado sistema de justiça penal americano (HORA; SCHMA; ROSENTHAL, 1999).

$\mathrm{Na}$ década de oitenta houve um crescimento vertiginoso dos delitos relacionados às drogas, o que levou a criação de leis mais duras sobre a temática e, consequentemente, um aumento muito importante nas taxas de criminalidade e de aprisionamento. A superpopulação carcerária, por sua vez, dificultava em muito a aplicação dos princípios educativos e socializadores da pena, enquanto que o uso de drogas por jovens aumentava de forma preocupante, sendo o crack a droga que despontava (FENSTERSEIFER, 2009). 
Ao final da década de oitenta foi verificado empiricamente que uma parte significativa dos crimes, das prisões e da reincidência criminal ocorria por conta das drogas, cujos acusados "eram pessoas que praticavam crimes sob o efeito de substâncias; eram infrações cometidas para a aquisição delas ou que violavam a lei penal por consumirem drogas" (LIMA, 2011, p. 97).

Diante desses achados, constatou-se que a criminalização do sujeito em razão da droga era cíclica, pois o sujeito praticava o delito, era preso, processado, condenado, cumpria sua pena, era posto em liberdade, voltava a consumir mais drogas e acabava se envolvendo em um novo delito. Verificou-se que $24 \%$ dos quatro milhões de adultos que se encontravam em Probation possuíam algum registro relacionado às substâncias entorpecentes e $20 \%$ dos presos estaduais, e 55\% dos federais, estavam presos por delitos relacionados às drogas (FULKESON; KEENA; O’BRIAN, 2012).

No ano de 1985, quase seiscentas e cinquenta mil pessoas estavam detidas por delitos relacionados às drogas, sendo que no ano de 1991 este número subiu para mais de um milhão. A consequência desse abrupto aumento das prisões e da aplicação de institutos como a Parole e a Probation tiveram como consequência uma expressiva quantidade de reincidência (HORA; SCHMA; ROSENTHAL, 1999). No ano de 2006, aproximadamente um milhão e meio de detenções decorrentes de posse de drogas foram registradas nos Estados Unidos, o que significa um aumento de 190\% desde 1982 (RENGIFO; STEMEN, 2010).

Com base nessas circunstâncias, um grupo de operadores do direito da cidade de Miami decidiu trabalhar para oferecer uma alternativa ao sistema tradicional que, como constatado, não estava se mostrando eficiente para lidar com a criminalidade relacionada às drogas. Assim, na metade do ano de 1989, no condado de Dade, em Miami na Flórida, por uma determinação administrativa do juiz Gerald Weatherington, foi instituída a primeira Corte de Drogas nos Estados Unidos, a qual foi elaborada a partir de colaborações imprescindíveis do juiz Herbert Klein (HORA; SCHMA; ROSENTHAL, 2009).

De acordo com Lima (2011), as Cortes de Drogas funcionam com a participação de juízes, defensores, promotores de justiça, além de profissionais da área da saúde, como psicólogos, médicos, assistentes sociais, bem como membros da comunidade e de instituições comunitárias que possam contribuir com o engajamento do participante no mercado de trabalho e em outras vias de reinserção. Os programas de tratamento eram divididos em três ou quatro fases, as quais tinham uma duração média de um ano, mas que frequentemente superavam esse tempo. Durante o tempo do programa o participante tinha o compromisso de 
participar de audiências, nas quais o magistrado podia supervisionar o andamento do tratamento conversando diretamente com o participante, podendo, ainda, aplicar sanções ou recompensas de acordo com o desempenho apresentado. Ao final do programa o sujeito passava por uma audiência de graduação.

De acordo com a proposta inicial elaborada pelos criadores da Corte de Drogas, os resultados foram satisfatórios e divulgados amplamente, sobretudo no território americano. As experiências foram aumentando e a sensação de eficácia das Cortes de Drogas foram tão positivas que no ano de 2011 os Estados Unidos já contavam com 2.193 Cortes de Drogas espalhadas pelo país (FULKESON; KEENA; O’BRIAN, 2012).

\section{AS CORTES DE DROGAS NO BRASIL: APORTES DE UMA HISTÓRIA RECENTE}

No Brasil, apesar do entendimento de parte da doutrina de que o programa originou-se a partir da promulgação do Estatuto da Criança e do Adolescente no ano de 1990 (LIMA, 2011), entende-se que a inspiração decorreu das Cortes de Drogas americanas em momento posterior ao referido marco legislativo.

Contudo, não se pode negar que os incisos V e VI do artigo 101, do ECA representam uma possibilidade legal de aplicação de um tratamento em vez da punição representada pela medida socioeducativa.

Em relação aos adultos, a Lei dos Juizados Especiais, Lei no 9.099/95, estruturou um procedimento mais célere e informal que serviu - e ainda serve - de plano de fundo para a aplicação de programas de Justiça Terapêutica. Na referida lei encontram-se diversos institutos que permitem a adoção de estratégias terapêuticas em relação ao acusado, como será visto mais adiante.

Já entre os anos de 1996 e 1997, foi desenvolvido pelo Ministério Público do Rio Grande do Sul o "Projeto Consciência", resultante de inúmeros encontros entre profissionais do direito e de áreas afins, que pensavam em alternativas à criminalidade relacionada ao consumo de drogas. No ano de 1998, por intermédio do Departamento de Recursos e Projetos Especiais - DRPE, do Ministério Público gaúcho, foi instituído o programa "RS sem Drogas", o qual, posteriormente, contanto com o apoio institucional do Poder Judiciário do Rio Grande do Sul, desenvolveu uma série de cursos de capacitação para Promotores de Justiça, Juízes de 
Direito, Advogados e Delegados de Polícia, de onde surgiu a nomenclatura "Justiça Terapêutica".

No início do ano de 2001 foi criado o Centro Integrado de Apoio da Rede Bioprisossocial - CIARB - que, dentre outras funções, tinha a atribuição de realizar a triagem das pessoas que a justiça lhe encaminhava aos programas de Justiça Terapêutica que operavam em Porto Alegre. O CIARB funcionava dentro do Foro Central de Porto Alegre e contava com equipe multidisciplinar responsável por fazer o elo de ligação entre a justiça e a rede pública de atendimento (FENSTERSEIFER, 2012).

Apesar de o Rio Grande do Sul ser considerado pioneiro nas práticas da Justiça Terapêutica, foi o Estado de Pernambuco que, em abril de 2001, inaugurou o primeiro Centro de Justiça Terapêutica, onde funcionava a Vara especializada em delitos relacionados a drogas e para onde a maioria dos atendimento relacionados à Justiça Terapêutica eram realizados.

Em setembro do ano seguinte o Rio de Janeiro instituiu um centro com condições e atribuições semelhantes. Atualmente diversos estados brasileiros possuem programas vinculados aos propósitos da Justiça Terapêutica, como São Paulo, Goiás, Rondônia, dentre outros.

O Rio Grande do Sul segue realizando projetos relacionados à Justiça Terapêutica, tanto na capital, como em algumas comarcas do interior. A comarca de Frederico Westphalen foi uma que elaborou um projeto piloto.

\section{OS RUMOS TOMADOS PELO PROGRAMA DE JUSTIÇA TERAPÊUTICA DE FREDERICO WESTPHALEN}

Elaborado um projeto preliminar, foi apresentada a proposta para o Poder Judiciário e para o Ministério Público da comarca de Frederico Westphalen. Depois de uma série de reuniões foi decidido que o programa iria ser destinado aos adolescentes infratores, em razão do expressivo número de crimes patrimoniais cometidos por adolescentes que eram motivados pelo uso da droga.

Tal circunstância vincula-se ao fato de que o período da adolescência corresponde à transição entre a infância e a adultez, no qual, segundo Jinez, Souza e Pillon (2009), o jovem fica exposto a maiores fatores de risco, tornando-se vulnerável. Nessa fase, o convívio com o grupo de amigos desempenha um papel importante, sendo esse mais valorizado em detrimento do relacionamento com pessoas diferentes de seus pares. 
Neste sentido, pesquisas realizadas com adolescentes em conflito com a lei no Brasil, em privação de liberdade, demonstram que a maioria apresenta como características distúrbios na conduta e uso de drogas, dados estes que coincidem com o perfil deste mesmo público nos Estados Unidos (MARTINS; PILLON, 2008). Ainda, conforme Maison e Windle (2002) apud Nardi, Filho e Dell'Aglio (2016) um estudo longitudinal com 1218 adolescentes mostrou que o uso de drogas pelos mesmos, do sexo masculino em conflito com a lei mantinha uma relação influente mútua com ações delitivas. Entende-se desta forma que é expressivo o número de jovens que se envolvem com comportamentos de risco, como o uso de drogas e a prática de atos infracionais.

A partir destes dados e do levantamento de demanda local realizado pelo Juiz e pela Promotora da comarca, o projeto de justiça terapêutica foi apresentado em abril de 2013, tendo suas atividades iniciadas em janeirode 2014, objetivandoimplantar de forma estruturada e regulamentada, de acordo com as diretrizes internacionais, o programa de Justiça Terapêutica para adolescentes na comarca de Frederico Westphalen. O projeto enfatizava como objetivos específicos: a) oferecer acompanhamento jurídico aos adolescentes participantes do programa; b) desenvolver atendimento psicoterápico aos adolescentes participantes do programa; c) disponibilizar serviço de atenção social às famílias dos adolescentes participantes do programa.

\section{A METODOLOGIA DE TRABALHO}

O projeto contou com a colaboração dos cursos de Direito, Enfermagem, Psicologia e Serviço Social da Universidade Regional Integrada do Alto Uruguai e das Missões - URI/FW.

O trabalho inicial a ser realizado pelo curso de direito configura-se como orientação e aconselhamento jurídico aos menores que forem encaminhados ao programa para que sejam garantidas todas as informações a respeito das implicações da aceitação, ou não, de ingresso no programa de Justiça Terapêutica. Tal assessoramento será realizado em seu primeiro contato com o juiz e com o órgão do Ministério Público, momento no qual será feita a proposta de inclusão no programa.

O Assistente social e o enfermeiro farão o acolhimento à família e uma entrevista inicial a fim de conhecer a dinâmica familiar e social que envolve esses atores, bem como 
formalizar a assinatura em termo de compromisso e aceite da inserção do adolescente no programa de Justiça Terapêutica.

Cabe ao Assistente Social identificar o contexto socioeconômico do sujeito, suas relações familiares, aspectos relacionados ao uso de drogas e as repercussões na vida do adolescente e de sua família, suas carências e demandas nas áreas de educação, saúde em geral, trabalho, previdência e outras. Ao enfermeiro cabe identificar possíveis problemas de saúde, uso e abuso de medicação, orientação, encaminhamento e acompanhamento à rede de saúde, bem como analise dos fatores de risco de saúde do adolescente e seu grupo familiar.

Após, o adolescente passará por uma entrevista com a psicologia para verificar se irá beneficiar-se com o tratamento breve. Além da entrevista, serão aplicados dois instrumentos - DUSI-R (Drug Use ScreeningInventory-Revised, questionário para triagem do uso de álcool, tabaco e outras substancias) e o Inventário de Estratégias de Copping de Folkman e Lazarus, com a finalidade de mapear a demanda do uso de substâncias do sujeito e como ele lida com situações estressoras.

Aos beneficiários sem indicação de tratamento específico no momento da avaliação, os atendimentos eram realizados com frequência quinzenal. Coordenados pelo Serviço Social, Direito e enfermagem, tinham cunho didático-terapêutico, cujo objetivo era promover uma reflexão sobre a importância do atual momento e como aproveitá-lo de forma benéfica. Os temas abordados eram relativos às drogas: prejuízos, tratamento, prevenção, fatores biopsicossociais envolvidos, violência e autoestima, bem como outros temas, tais como: família, saúde, sexualidade, cidadania, etc. além de estimular a organização e participação social em grupo.

Posteriormente, o adolescente participava do programa de psicoterapia de 10 sessões $^{1}$ padronizadas e manualizadas, compostas por estratégias terapêuticas, com abordagem cognitivo-comportamental. A psicoterapia é um tratamento psicológico que tem por objetivo modificar pensamentos, sentimentos e comportamentos-problema, criando um novo entendimento dos pensamentos e sensações responsáveis pela dificuldade ou problema observado.

O objetivo da psicoterapia inicialmente era transformar o encaminhamento judicial em motivação interna para o tratamento, trabalhar estratégias preventivas para controle da compulsão ao uso indevido de drogas, mapear situações predisponentes, precipitantes e mantenedoras do consumo de drogas e trabalhar a prevenção à recaída. Também, buscava-se reduzir a reincidência do consumo de drogas e as consequências 
negativas diretas e indiretas, reconhecer, estimular e desenvolver capacidades e habilidades individuais, aumentando a autoestima e autoeficácia do paciente, descortinando desta forma novas possibilidades de vida e futuro mais satisfatórias. No caso de psicopatologias mais graves associadas, era-se encaminhado o paciente usando a rede social.

Dentre os diferentes tipos de tratamento, a abordagem cognitiva comportamental foi eleita por vir demonstrando bons resultados no tratamento de comportamentos aditivos, visto que integra técnicas e conceitos das duas abordagens. Esta terapia é cientificamente fundamentada e utiliza-se de procedimentos ativos, diretos e estruturados. (CHRIST, FACCHIN E GAUER, 2012).

Após as dez sessões, os instrumentos eram novamente aplicados, visando a avaliação da eficiência do tratamento e, o resultado do teste-reteste, serviria como base para reformulações necessárias para alcançar os objetivos do projeto.

A equipe técnica do Programa de Justiça Terapêutica recebe os relatórios periódicos sobre o tratamento dos beneficiários, elaborados pelas Instituições conveniadas (rede pública de saúde e assistência social), nos quais devem constar se os mesmos tinham comparecido ao tratamento e se estavam beneficiando-se deste. Tanto essas informações, bem como quaisquer alterações importantes ocorridas durante todo período de cumprimento da Medida, eram transmitidas ao juízo mensalmente, salvo quando a equipe de saúde entendesse que a informação deveria ser passada imediatamente, em casos de falta do paciente, por exemplo.

Os profissionais que compunham o programa de Justiça Terapêutica se reuniam sistematicamente de modo a promover troca de informações e estudo de casos, dentre outras atividades, objetivando sempre o aprimoramento do programa.

Por fim, os participantes que concluíssem o programa teriam seus procedimentos extintos enquanto que aqueles que desistissemseriam excluídos do programa tendo seus processos recolocados em andamento desde onde haviam sido suspensos.

6 O SURGimento de UM FATO NOVO ALHEIO AO PROGRAMA DE JUSTIÇA TERAPÊUTICA

A população alvo do programa era composta por adolescentes em conflito com a lei. Isso porque, após diversas reuniões com o Juiz e com o Promotor de Justiça envolvidos no projeto, essa população foi sugerida por eles em razão do grande número de processos 
envolvendo jovens usuários de droga que praticavam diversos delitos, sobretudo patrimoniais, em busca de dinheiro para comparem drogas.

Apesar desse contexto favorável ao desenvolvimento do programa, sobreveio fato superveniente e incontrolável que inviabilizou a sua continuidade.

Ao longo do período que antecedeu a execução do projeto, especialmente entre o seu início e o seu desenvolvimento, foram executadas diversas operações policiais na região as quais desencadearam a prisão de alguns traficantes de drogas, especialmente em Frederico Westphalen. Segundo conversas informais ocorridas no Fórum e no Presídio local, soube-se que muitas dessas prisões foram possíveis a partir de delações praticadas por dependentes de crack, o que, segundo foi informado, fez com que os traficantes remanescentes e/ou substitutos deixassem de comercializar a droga, reduzindo consideravelmente o seu consumo.

Como consequência disso, os adolescentes que consumiam crack deixaram de o fazer e consequentemente se afastaram dos delitos que usualmente praticavam para sustentar o vício.

O reflexo foi visível na comarca e na região que, embora não conte com estudo associando todas essas informações de cunho especulativo, registrou uma importante queda na criminalidade, representada em quase $50 \%$ a menos,conforme dados oficiais noticiados pela imprensa local (O ALTO URUGUAI, 2014).

Dessa forma, a população que era relativamente alta, tornou-se escassa e o trabalho foi raro para os alunos bolsistas e professores da universidade que estavam envolvidos, com o que não houve viabilidade financeira para a instituição de ensino seguir patrocinando a execução do projeto de extensão, uma vez que, dado o contexto, não possuía o retorno científico e social esperado.

\section{OS (POUCOS) RESULTADOS OBTIDOS NO PROGRAMA DE JUSTIÇA TERAPÊUTICA DE FREDERICO WESTPHALEN}

Durante o tempo em que o programa estava funcionando, três adolescentes foram encaminhados para atendimento.

Os participantes encaminhados responderam aos testes psicológicos e iniciaram o tratamento, sendo que o primeiro desistiu na $7^{\mathrm{a}}$ sessão, o segundo abandonou na $2^{\mathrm{a}}$ devido a 
uma psicopatologia grave que dificultava a adesão ao tratamento e o terceiro descontinuou o processo terapêutico na $2^{\mathrm{a}}$ devido à mudança de cidade. Este último procurou novamente pelo atendimento meses depois, mas não conseguiu aderir ao tratamento pela presença de uma psicopatologia comórbida.

Considerando a desistência nos atendimentos no que condiz a dependência química, a própria literatura nos traz que a adesão ao tratamento, principalmente de adolescentes é bastante difícil. Isso ocorre devido a fatores extrínsecos ao adolescente e ao atendimento, podendo a sua relação com o meio social e situações concretas de vida facilitar ou dificultar o acesso ao tratamento. É consenso que, apesar das diversas teorias e técnicas voltadas ao tratamento de dependência química, ainda há uma grande dificuldade em o paciente aderir de fato aos tratamentos propostos (SCADUTO; BARBIERI, 2009). No entanto, tentativas motivacionais de mudança de comportamento e hábitos de vida não saudáveis devem ser buscadas com o intuito de buscar alternativas mais benéficas aos usuários.

Em suma, a função do terapeuta nesta fase é de auxiliar o paciente a compreender a ligação entre seus sentimentos e suas condutas no presente, promovendo na sessãopsicoterápica um espaço de reflexão (ZAVASCHI;et al,2008). Desta forma, a psicoterapia com o adolescente vai ao encontro da resolução de seus problemas e conflitos, de forma a resolvê-los de forma saudável e assertiva, promovendo saúde e bem estar, e prevenindo inclusive o uso de substâncias como forma de fugir dos seus problemas.

Atualmente a comarca de Frederico Westphalen conta com uma média de 30 adolescentes em cumprimento de medida socioeducativa. Destes números, é importante ressaltar que nenhum deles encontra-se em medida de internação ou apresenta problemas decorrentes do uso de drogas.

Somando-se a baixa demanda do projeto com a dificuldade de adesão especialmente dos jovens ao tratamento, não houve, nesses seis meses de funcionamento, nenhum adolescente que concluísse o programa.

\section{CONSIDERAÇÕES FINAIS: A HERANÇA DO PROJETO DE JUSTIÇA TERAPÊUTICA DA COMARCA DE FREDERICO WESTPHALEN/RS}

Para os próximos anos, contudo, pensa-se em desenvolver e fortalecer um projeto de extensão que vem sendo aplicado sobre violência doméstica aqui na comarca a partir da 
utilização de práticas da Justiça Terapêutica e da Justiça Restaurativa, sempre no sentido de buscar a humanização da prestação jurisdicional do ponto de vista da TherapeuticJurisprudence.

O projeto desenvolvido em Frederico Westphalen, embora não tenha tido a utilização esperada, permite o desdobramento de outras práticas terapêuticas e da sua repaginação em outros cenários, tanto no que diz respeito à população alvo bem como em relação à sua replicação em outras comarcas do interior.

A importância do presente projeto evidencia-se na medida em que se possibilita o desenvolvimento do programa de Justiça Terapêutica sem a necessidade de aprovação de legislação específica para tanto, bem como a partir de recursos da rede pública de saúde e da assistência social existente nos municípios. O principal desafio, mas não inacessível, talvez, seja o de configurar a ligação entre o Poder Judiciário, o Ministério Público e essa rede municipal.

Considerando-se as peculiaridades de cada comarca e município, e adequando-as conforme a singularidade de cada local subentende-se que este plano de tratamento poderia ser aplicado em outros contextos, como forma de diminuir a reincidência de atos delituosos por adolescentes usuários de substâncias psicoativas, bem como promover uma melhora significativa à qualidade de vida do adolescente. Esta é uma opção que vai ao encontro da promoção e prevenção no que condiz a saúde e a justiça, uma opção para diminuir os processos judiciais, economizar no tempo e na economia e além de tudo, buscar a diminuição da reincidência dos casos. Como contraponto a este trabalho, podemos pensar no modelo de aplicação das medidas socioeducativas que vem sendo aplicadas atualmente, na qual o embasamento teórico é muito bem escrito, porém na práxis percebe-se que ela vem sendo aplicada como um modelo punitivo aos adolescentes e não de tratamento e prevenção como propomos neste trabalho.

Porém, para que este projeto fizesse parte realmente da realidade de nossascomarcas, seria necessário à implementação e a disseminação das ideias de forma diferenciada a que acontece em outros países, ou seja, que a criação de uma Vara específica para tratar destes casos não fosse empecilho para o desenvolvimento do projeto.Assim, constatou-se neste primeiro momento que a falta de legislação específica para implementar este projeto não ocorreu como empecilho para o seu desenvolvimento,mas o contrário, teve uma boa aceitação tanto da parte judiciária quanto da rede de assistência e saúde. 
Ainda, de forma similar, este projeto poderia ser reeditado e adequado para tratar de outros casos referentes ao uso de substâncias, ocorrências em que a tempo a forma punitiva da legislação não surte mais efeito. Cita-se nestes casos, o acompanhamento terapêutico nos fatos de Maria da Penha ou de Justiça Restaurativa/Mediação, onde há possibilidades de trabalhar com os ofensores, além do tratamento para dependência química, a resolução de problemas, assertividade, bem-estar e principalmente, descortinar possibilidades de vida, trabalhando-se desta forma para a diminuição da reincidência da violência, diminuindo os casos tanto no que tange a justiça quanto à saúde (visto que a violência é um fator que acomete a saúde tanto de forma física quanto psicológica).

Porém, apesar de todas estas informações e esboços de planejamento do trabalho, é inevitável que nele encontrem-se algumas limitações. Estas podem ser citadas quando por exemplo, o paciente devido a alguma comorbidade não consegue aderir ao tratamento ou então, adere com intenções secundárias (cita-se aqui o caso de psicopatas). Outra limitação imposta no momento é a falta de dados precisos sobre a eficácia do trabalho aplicado aqui no Brasil e, especialmente em Frederico Westphalen. O que sabemos, contudo, é que o atual modelo punitivo não se mostra minimamente eficiente, enquanto que a Justiça Terapêutica apresenta uma possibilidade nova, menos punitiva e que possui bons resultados, tanto do ponto de vista individual quanto do social (FENSTERSEIFER, 2015).

Como já citado, através deste programa, os órgãos da justiça, principalmente, acabaram por se unirem mais, através da ponte feita pela Universidade local, e acionando a rede de assistência e saúde quando necessárias. Este ponto que se mostrou bastante positivo poderia ser melhor aproveitado, principalmente tornando-se a discutir a reaplicação e renovação do projeto na Comarca, aprimorando este trabalho de grande valia para diferentes casos e contextos, priorizando sempre através dele, poder olhar para o sujeito de forma diferenciada, tratando-o e não punindo e buscando por fim mais qualidade de vida para todos os cidadãos através da diminuição da reincidência criminal.

\section{REFERÊNCIAS}

CARLINI, E. A ; (supervisão)et. al. (2006).II Levantamento Domiciliar Sobre o Uso de Drogas Psicotrópicas no Brasil: estudo envolvendo as 108 maiores cidades do país. São Paulo: CEBRID - Centro Brasileiro de Informações Sobre Drogas Psicotrópicas: UNIFESP Universidade Federal de São Paulo. Disponível em: http://www.cebrid.epm.br/index.php acesso em: 13 jun. 2012. 
CARLINI, E. A; (supervisão)et. al. (2010).VI Levantamento Nacional sobre o Consumo de Drogas Psicotrópicas entre Estudantes do Ensino Fundamental e Médio das Redes Pública e Privada de Ensino nas 27 Capitais Brasileiras. São Paulo: CEBRID - Centro Brasileiro de Informações sobre Drogas Psicotrópicas: UNIFESP - Universidade Federal de São Paulo. Disponível em: http://200.144.91.102/cebridweb/default.aspx acesso em: 13 jun. 2012.

CARLINI, E. A; et. al.(2002). I Levantamento Domiciliar sobre o Uso de Drogas Psicotrópicas no Brasil: Estudo Envolvendo as 107 Maiores Cidades do País: 2001. São Paulo: CEBRID - Centro Brasileiro de Informações Sobre Drogas Psicotrópicas: UNIFESP Universidade Federal de São Paulo. Disponível em: http://200.144.91.102/sitenovo/conteudo.aspx?cd=640. Acesso em: 31 ago. 2015.

CHRIST, H. D.; FACCHIN, T. H. J.; GAUER, G. J. C. Tratamento CognitivoComportamental para transtorno antissocial.In: GAUER, G. J. C. VASCONCELLOS, S. J. L.; DAVOGLIO, T. R. (Org.) Adolescentes em conflito: violência, funcionamento antissocial e traços de psicopática. São Paulo: Casa do Psicólogo, 2012.

FENSTERSEIFER, D. P., (2012), Varas de Dependência Química no Brasil: Um debate realizado a partir de observações da experiência canadense com DrugTreatmentCourts. Porto Alegre: Núria Fabris.

FENSTERSEIFER, D. P. (2015). Os primeiros passos do programa de justiça terapêutica da comarca de Frederico Westphalen. In: FENSTERSEIFER, Daniel Pulcherio (coord.). Curitiba: Juruá.

FENSTERSEIFER, Daniel Pulcherio. A Droga como Fator de Risco para a Violência e a Justiça Terapûtica como Mecanismo de redução do Dano. In: FAYET JR. Ney; MAYA, André Machado (orgs.) Ciências Penais e Sociedade Complexa. Porto Alegre: Núria Fabris, 2009.

FULKERSON, Andrew; KEENA, Linda D.; O'BRIAN, Erin. Understanding Success and Nonsuccess in the Drug Court. In: International Journal of Offender Therapy and Comparative Criminology. 2012. Disponívelem: http://ijo.sagepub.com/content/57/10/1297. Acessoem: 24 de set. 2014.

GALDURÓZ, José Carlos F.; et al. V Levantamento Nacional Sobre o Consumo de Drogas Psicotrópicas Entre Estudantes de Ensino Fundamental e Médio da Rede Pública de Ensino das 27 Capitais Brasileiras. São Paulo: CEBRID - Centro Brasileiro de Informações Sobre Drogas Psicotrópicas: UNIFESP - Universidade Federal de São Paulo, 2004. Disponível em: http://www.cebrid.epm.br/levantamento_brasil2/pp001a010.pdf. Acesso em: 01 de jul. 2016.

HORA, Peggy Fulton; SCHMA, William G.; ROSENTHAL, John T. A. Therapeutic Jurisprudence and the Drug Teratment Court Movement: revolutionizing the criminal justice system's response to drug abuse and crime in America. NotreDame Law Review. 74. 1999. pp. 439-538.

JINEZ, M. L. J.; SOUZA, J. R. M.; PILLON, S. C. (2009). Uso de drogas e fatores de risco entre estudantes de ensino médio. In: Ver. Latino-am Enfermagem. Mar-Abr; 17(2). 
LIMA, Flávio Augusto Fontes de. Justiça Terapêutica: em busca de um novo paradigma. São Paulo: Scortecci, 2011.

MARTINS, M. C.; PILLON, S. C. (2008). A relação entre a iniciação do uso de drogas e o primeiro ato infracional entre os adolescentes em conflito com a lei. Cad. Saúde Pública vol.24 no.5 Rio de Janeiro. Disponível em: http://www.scielo.br/scielo.php?script=sci_arttext\&pid=S0102311X2008000500018\&lang=p > Acesso em: 11.07.2016

NARDI, F. L.; FILHO, N. H.; DELL'AGLIO, D. D. (2016). Preditores do Comportamento Antissocial em Adolescentes. Psic.: Teor. e Pesq. vol.32 no.1 Brasília [online]. Disponível em: $<$ http://www.scielo.br/scielo.php?script=sci_arttext\&pid=S010237722016000100063\&lan $\mathrm{g}=\mathrm{pt}>$ Acesso em: 11.07.2016

O ALTO URUGUAI. Frederico Westphalen, págs. 04-05, 23 de ago. de 2014.

RENGIFO, Andres F.; STEMEN, Don.The Impact of Drug Treatment on Recidivism: do mandatory programs make difference? Evidence from Kansas's Senate Bill 123. In: Crime \& Delinquency. 2010. Disponívelem: http://cad.sagepub.com/content/59/6/930. Acessoem: 24 de set. 2014.

SCADUTO, A. A; BARBIERI, V. (2009). O discurso sobre a adesão de adolescentes ao tratamento da dependência química em uma instituição de saúde pública. Ciênc. saúde coletiva. Vol.14, No.2, Rio de Janeiro. Disponível em: $<$ http://www.scielo.br/scielo.php?script=sci_arttext\&pid=S1413-

81232009000200029> Acesso em: 02.09.15

TAVARES, G. P.; SHEFFER, M.; ALMEIDA, R. M. M. (2012). Drogas, Violência e Aspectos Emocionais em Apenados. In: Psicologia: Reflexão e Crítica. 25(1), 89-95.

VIEIRA, E. M; PERDONA, G.S. C; SANTOS, M. A. (2011). Fatores associados à violência física por parceiro íntimo em usuárias de serviços de saúde. In: Revista de Saúde Pública; 45(4): $730-7$.

ZAVASCHI, M. L. S; BASSOLS, A. M; SALLE, E; MALTZ, F. F; SANTIS, M. B. (2008). Psicoterapia na adolescência. In: CORDIOLI, A. V. (org). Psicoterapias: abordagens atuais. Porto Alegre: Artmed. p. 760-776.

ZILBERMAN, M. L; BLUME, S. B. (2005). Violência doméstica, abuso de álcool e substâncias psicoativas. In: Revista Brasileira de Psiquiatria: 27 (supl. II) S51-5. 
Cortes de Drogas no Brasil: a herança do Projeto de Frederico Westphalen/RS

\footnotetext{
${ }^{1}$ Sessão 1 - Levantamento de dados para compreensão do caso e contrato terapêutico.

Sessão 2 - Psicoeducação sobre TCC e mapeamento de fatores predisponentes, precipitantes e mantenedores do uso de drogas.

Sessão 3 - Entrevista motivacional.

Sessão 4 - Identificação e manejo da fissura.

Sessão 5 - Levantamento de situações estressoras.

Sessão 6 - Trabalho da impulsividade e tolerância à frustração.

Sessão 7 - Resolução de problemas.

Sessão 8 - Avaliação motivacional e projeto de vida.

Sessão 9 - Devolução/ avaliação do tratamento com o adolescente.

Sessão 10 - Devolução/ avaliação do tratamento com os responsáveis e encaminhamento (se necessário).
}

Artigo recebido em 18 de julho de 2016 e aceito em 10 de junho de 2017 